\title{
İş zekası uygulamaları seçimindeki kriterlerin önem ağırlıklarının FUCOM yöntemi ile belirlenmesi*
}

Ejder Ayçin ${ }^{1}$

Doç.Dr., Kocaeli Üniversitesi

ejder.aycin@kocaeli.edu.tr

(1) 0000-0002-0153-8430
Hakan Așan

Arş.Gör., Dokuz Eylül Üniversitesi

hakan.asan@deu.edu.tr

(D) 0000-0001-9550-3345

\section{öZ}

Günümüzde büyük veri tabanlarının ortaya çıkmasıyla birlikte, işletmeler iç ve dış kaynaklardan olmak üzere daha fazla veriyi saklayabilir hale gelmișlerdir. Bu değerli veri kaynaklarının doğru ve başarılı şekilde bilgiye dönüştürülmesi iş zekası uygulamaları ile mümkündür. İşletmelerin sahip olduğu kurumsal kaynak planlama yazılımları, kendi iç yapılarında bazı raporlama özellikleri sunmaktadırlar. Ancak işletmeler, hem farklı kaynakların bir araya getirilmesi hem de sadece özel bir amaca göre geliştirilmeleri nedeniyle iş zekası uygulamalarına ihtiyaç duymaktadırlar. İş zekası uygulamaları verinin değerli bilgiye dönüşümünde farklı enstrümanlar kullanmaktadır. Bu nedenle iş zekası uygulamaları birçok farklı özelliğe sahiptirler. İşletmeler açısından bakıldığında ise farklı birçok özelliğin var olması, iş zekası uygulaması seçimini zor ve karıșı bir hale getirmiştir. Bu durum mevcut çalışmanın çıkış noktasını oluşturmuştur. Öncelikle iş zekası uygulaması seçimi aşamasında dikkate alınan üç ana kriter ve bu ana kriterlere bağlı yirmi bir alt kriter belirlenmiștir. Ardından bu kriterlerin önem ağırlıklarının subjektif bir kriter ağırlıklandırma yöntemi olan FUCOM (Full Consistency Method) ile hesaplandığı bir uygulama gerçekleștirilmiştir. Uygulama sonuçlarına göre en önemli kriterlerin sırasıyla farklı platformlarda kullanım, uyarlama maliyeti ve kullanıcı ara yüzü etkileşimi olduğu tespit edilmiștir.
Anahtar Kelimeler: İș Zekası, Çok Kriterli Karar Verme, FUCOM JEL Kodları: C44, M15

\section{Determination of the weight coefficients of criteria in the selection of business intelligence applications with FUCOM}

\begin{abstract}
Nowadays, with the emergence of large databases, businesses have become able to store more data, both internal and external sources. It is possible to transform these valuable data sources into information correctly and successfully with business intelligence applications. Enterprise resource planning software owned by businesses offers some reporting features in their own internal structures. However, businesses need business intelligence applications due to both the combination of different resources and the fact that they are developed only for a specific purpose. Business intelligence applications use different instruments in the transformation of data into valuable information. Therefore, business intelligence applications have many different features. From the point of view of businesses, the existence of many different features has made the choice of business intelligence application difficult and complex. This situation constituted the starting point of the current study. First of all, three main criteria were taken into consideration at the stage of business intelligence application selection, and twenty-one sub-criteria related to these main criteria were determined. In addition, an application was carried out in which the weights of these criteria were calculated with FUCOM (Full Consistency Method), a subjective weighting method. According to the application results, it has been determined that the most important criteria are usage on different platforms, customization cost, and user interface interaction, respectively.
\end{abstract}

Keywords: Business Intelligence, Multi Criteria Decision Making, FUCOM

JEL Codes: C44, M15

\footnotetext{
*Atıf vermek için/To cite: “Ayçin, E., \& Aşan, H. (2021). İş zekası uygulamaları seçimindeki kriterlerin önem ağırlkklarının FUCOM yöntemi ile belirlenmesi. KOCATEPEIIBBFD, 23(2), 195-208. https://doi.org/10.33707/akuiibfd.903563

Sorumlu Editör/Handling Editor: Prof.Dr. Fatih Ecer

1 Sorumlu Yazar/Corresponded Author
} 


\section{Extended Summary}

Today, with the emergence of large databases, businesses have become able to store more data from internal and external sources. Processing these data in a short time and turning them into reports, visuals, and graphics that can be easily perceived by decision-makers is possible with business intelligence applications. Enterprise resource planning software used by businesses offers some of the reporting features in their internal structure. However, businesses need business intelligence applications due to the combination of different resources and the development of them only for a specific purpose. Business intelligence tools and processes enable end-users to identify actionable information from raw data, facilitating data-driven decision-making within businesses in a variety of industries.

The selection of business intelligence applications, which are extremely important in terms of visualizing data and transforming it into valuable information, is an important and difficult decision for businesses. There are many different features of business intelligence applications and decision-makers evaluate many options in selecting business intelligence applications. In the evaluation phase, various criteria related to both the business and the software were taken into consideration.

The idea of determining which of the selection criteria is more important for businesses has formed the starting point of this study. In this direction, it is aimed to realize an application in which the weight coefficients of the criteria are calculated with FUCOM (Full Consistency Method), which is a subjective weighting method. FUCOM is a linear programming-based method that needs fewer pairwise comparisons than other weighting methods and provides a consistent pairwise comparison of criteria. This method enables the precise determination of the values of the weight coefficients of all elements mutually compared at a certain level of the hierarchy, simultaneously satisfying the conditions of the comparison consistency. In addition, the FUCOM method, which makes calculations using evaluations based on expert opinions, is suitable for solving problems that mostly involve qualitative criteria, such as the selection of business intelligence applications.

In the application part of the study, first of all, three main criteria taken into consideration during the selection of business intelligence application and twenty-one sub-criteria related to these main criteria were determined. During the determination of the criteria, the literature review and the opinions of experts working in the Information Technology (IT) sector were used. According to the weight coefficients of criteria obtained by the FUCOM method, the three most important criteria are usage on different platforms, customization cost and user interface interaction, respectively. The three least important sub-criteria are cloud support, big data analysis and GIS support respectively. Findings revealed that experts attach more importance to visual elements in business intelligence applications, and basic usage features and cost criteria are also important. The study creates a model for the criteria to be considered for the selection of business intelligence, which is an extremely difficult and important decision for businesses, and for calculating the weight coefficients of these criteria.

Since there are a limited number of studies in the literature in which business intelligence applications are related to multi-criteria decision-making methods, it is expected that the current study will contribute to the literature in this respect. The possibility of changes in the results to be obtained with the opinions of different experts is among the limitations of this study. In future studies, different criteria structures can be examined or similar criteria structures can be analyzed with fuzzy logic and integrated criteria weighting methods (fuzzy SWARA, fuzzy BWM, fuzzy FUCOM, etc.). In addition, studies can be conducted to evaluate business intelligence applications by using the methods used for alternative ranking purposes such as TOPSIS, MABAC, MARCOS, WASPAS. 


\section{Giriş}

İşletmeler açısından veriyi kayıt altına almak oldukça önemlidir. Gelişen teknolojilerle birlikte veriyi düzenli bir şekilde kayıt altına almak son derece kolay hale gelmiştir. Kurumsal kaynak planlaması ve bu sistemlerle birlikte çalışan fonksiyonel bilgi sistemlerinin yaygın kullanımı da verinin kaydedilmesinde etkili rol oynamaktadır. Verinin istenilen zamanda erişilebilir olmasının işletmeler açısından birçok katkısı olmaktadır. Özellikle bu verilerin raporlanması geçmişi farklı açılardan değerlendirebilme ve geleceğe dair tahminleme yapmak açısından son derece önemlidir. Kurumsal kaynak planlama yazılımları, bünyelerinde raporlama seçenekleri sunabilmekte ancak bu raporlar özellikleri açısından çoğunlukla standart özellikler taşımaktadır. Genel kullanıcılar için tasarlanan bu raporlar beklentileri karşılayamadığından, bu durum işletmeleri iş zekâsı yazılımları satın almaya yöneltmektedir.

İş zekâsı yazılımları birçok farklı veri kaynağı ile bağlantı kurabilmekte ve verileri parametrik olarak sorgulama imkânı sunabilmektedir. Görsel öğelerle kullanıcıların dikkatini belli noktalara yoğunlaştırabilmektedirler. Her yeni yazılım seçimi gibi iş zekâsı seçimi da işletmeler açısından önemli bir karardır. İş zekâsı yazılımlarının seçim kararı verilirken birçok kriter göz önünde bulundurulmaktadır. Bu kriterlerin birbirlerine göre kıyaslanması ve hangi kriterin daha önemli olduğunun belirlenmesi fikri bu çalışmanın çıkış noktasını oluşturmuştur. Kriterlerin önem ağırlıklarının hesaplanması amacıyla, çok kriterli karar verme (ÇKKV) literatürüne son yıllarda girmiş subjektif bir kriter ağırlıklandırma yöntemi olan FUCOM (Full Consistency Method) yönteminden yararlanılmıştır. FUCOM yöntemi Analitik Hiyerarşi Süreci (AHP), Best-Worst Metodu (BWM) ve DEMATEL gibi kriter ağırlıklandırma amacıyla kullanılan diğer yöntemlerle kıyaslandığında, çok daha az sayıda ikili karşılaştırma ile çözüm yapmaya olanak tanımaktadır. Karar probleminde " $n$ " adet kriterin bulunması durumunda, FUCOM yöntemiyle çözüm yapmak için " $n-1$ " adet ikili karşılaştırma gerekliyken, bu sayı AHP'de "n(n-1)/2", BWM'de (2n-3) adettir (Ecer, 2020). Daha az ikili karşılaştırma ile daha tutarlı çözüm yapabilme olanağı sağlaması, FUCOM yönteminin bu çalışmada tercih edilmesinin temel nedenlerinden biri olmuştur. Ayrıca iş zekası uygulamalarının seçimi gibi nitel kriterlerin çoğunlukta olduğu problemlerde, uzman görüşüne dayalı değerlendirmeler ile karar verici görüşlerinin sayısallaştırılarak kriterlerin önem ağırlıklarının hesaplanabilmesi FUCOM yöntemiyle mümkün olabilmektedir. Uygulama adımlarının karmaşık olmaması ve oluşturulan doğrusal programlama modellerinin Excel Solver, Lindo, Lingo vb. programlar ile rahatlıkla çözülebilir olması, yöntemin önemli avantajlarından biri olarak görülmektedir.

Bu doğrultuda, çalışmanın ilk bölümünde iş zekası kavramı açıklanmıştır. Ardından iş zekası yazılımı seçiminde ÇKKV yöntemlerinin kullanıldığı çalışmalar ile FUCOM yönteminin kullanıldığı bazı çalışmaların yer aldığı literatür taramasına yer verilmiştir. FUCOM yöntemi ile ilgili teorik bilgi aktarıldıktan sonra, iş zekası yazılımı seçiminde ele alınan kriterlerin önem ağırlıklarının hesaplanmasına yönelik bir uygulama yer almıştır. Kriterler değerlendirilirken bilgi teknolojisi departman yöneticilerinden oluşan bir gruptan görüş alınmıştır. Son olarak FUCOM ile çözüm gerçekleştirilmiş ve sonuçlar değerlendirilmiştir. İşletmeler açısından son derece önemli olan iş zekası yazllımı seçiminde dikkate alınan kriterlerin, literatürde yer alan yeni yöntemlerden biri olan FUCOM yöntemi ile değerlendirildiği bu çalışmanın literatüre katkı sağlaması hedeflenmektedir.

\section{II. İş Zekası}

İş zekası kavramı literatürde Hans Peter Luhn tarafından ilk defa 1958 tarihinde kullanılmıştır (Luhn, 1958). Şu an literatürde kabul gören iş zekası tanımı ise Gartner şirketinin analistlerinden Howard Dresner tarafından 1989 yılında yapılmıştır. Dresner, iş zekasını şemsiyeye benzetmiştir. İş zekasını, karar verme sürecini desteklemek ve iyileștirmek için veriyi kullanan destek sistemlerinde kullanılan tüm kavram ve yöntemler (mimari, iş süreci ve teknoloji) olarak tanımlamıștır (Karim, 2011). İş zekasının temelde benzer olmakla beraber birçok tanımı bulunmaktadır. İş zekası, işlenmemiş verinin karar destek amacıyla yararlı ve anlamlı bilgiye dönüştürülmesi işlemidir. Bu işlemi çok kısa zamanda yapabilen ve çok büyük miktarda veriyi işleyip karar vericiler açısından kolaylıkla algılanabilecek raporlar, görseller ve grafikler oluşturabilen sistemlerdir (İş Zekası ve Ötesi, 2014). Diğer bir tanım incelendiğinde, iş zekası, bütün kaynaklardan bir araya getirilen verilerin, bilgiye dönüşmesi için iş ile ilgili, bilinçli, sistematik ve sonuca yönelik işlemlerinin tümü olarak tanımlanmıştır (Mike, 2013). Moss ve Atre ise iş zekasını, işletme çalışanlarının işle ile alakalı verilere kolaylıkla erişebilmesi için kullanılan veri tabanları, bütünleşik işlemler ve karar destek sistemlerinden bir araya gelen yazılım mimarisidir şeklinde tanımlamıștır (Moss ve Atre, 2003). İşletmelerin, iç ve dış kaynaklarından veri toplamasına, analiz edilebilir ön işlemle işlemlerinin yapılabilmesine, geliştirmesine ve veriye dayalı sorgular oluşturulmasını sağlar (Pavkov vd., 2016). İş zekası araçları ve süreçleri, son kullanıcıların ham verilerden eyleme geçirilebilir bilgileri tanımlamasına olanak tanıyarak çeşitli sektörlerdeki kuruluşlar içinde veriye dayalı karar vermeyi 
kolaylaştırır (IBM, 2021). İş zekâsı sistemlerinin özellikleri ve sağladığı avantajlar aşağıdaki şekilde sıralanmıștır (Khan, 2012; Pavkov vd., 2016):

- İşletmeye ait iç ve dış verilerin bir araya getirilmesi ve bu verilerin en iyi şekilde kullanılması

- Geçmiş dönem ve güncel verilere kolay erişim sağlanması ve karşılaştırmalı güçlü analizlerin yapilabilmesi,

- Karar verme süreçlerine özellikle operasyonel ve stratejik departmanlarda hız ve etkinlik sağlaması,

- İş̧ süreçlerinin iyileștirilmesinin sağlanması,

- Önemli bilgi çıktılarının sağlanması,

- Kısa zamanda işlem yapabilme yetisi ile bilgiye zamanında ulaşmanın sağlanması,

- Sistem kullanıcılarının sadece ihtiyacı olan bilgiyi elde ederek, karmaşadan kurtararak kullanıcıya fayda sağlaması,

- Verilerin görsel öğelerle sunulması,

- Yeni iş firsatlarının ortaya çıkmasına imkan vermesi,

- Sağlamış olduğu bilgi ile iş ve rekabet avantajı sağlaması,

- Bilgi teknolojilerine ihtiyaç duyulmadan, son kullanıcının verileri analizine imkan sağlaması,

- Benzersiz raporlar oluşturabilmesi,

- Daha stabil ve kesin bilginin sağlanması.

İş zekası uygulamaları işletme içinde birçok birim tarafından kullanılmaktadır. İşletmelerde iş zekası uygulamalarını sıklıkla kullanan birimler aşağıda gösterilmiştir (Horakova ve Skalska, 2013);

- Pazarlama, satış, müşteri ilişkileri yönetimi,

- Lojistik, üretim, satın alma,

- Finansman, kalite kontrol,

- Web analizi, Arama motoru optimizasyonu,

- İnsan kaynakları yönetimi,

- Bilgi iletişim yönetimi, vb.

İşletmelerin kullandığı birçok iş zekası uygulaması bulunmaktadır. Ortak olarak aynı işi yapmalarına rağmen kullandıkları yöntemler ve teknolojiler anlamında birbirlerine göre farklılıkları bulunmaktadır. Bağımsız bir araştırma şirketi olan Gartner, yıllık yayınladığı bir raporda, yaygın kullanılan iş zekası uygulamalarını çeșitli kriterlere göre sınıflandırmaktadır. Şekil 1'de 2020 yılına ait bir sınıflandırma gösterilmiştir.

Şekil 1: 2020 İş Zekası Uygulamaları

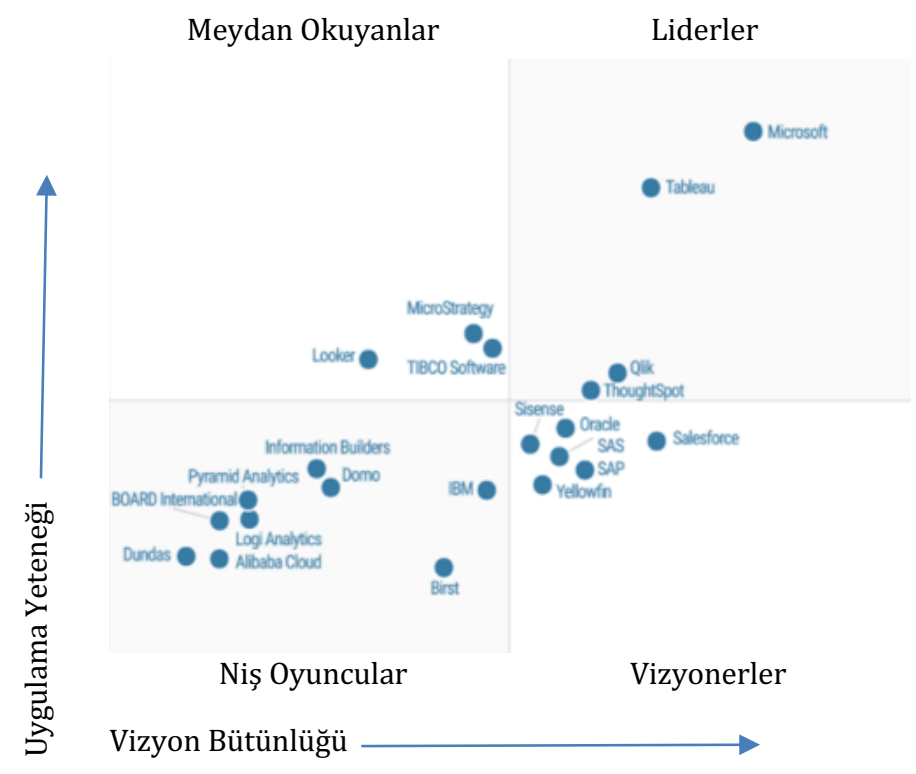

Kaynak: (Gartner Magic Quadrant Report, 2020)

Gartner sıralamasına göre pazar lideri olarak konumlandırılan firmalar Microsoft, Tableau, Qlik ve ThoughtSpot olarak tespit edilmiştir. Business Intelligence Software web sitesi, 2021 yılına ait kullanıcı ve analist geri bildirimlerine dayalı raporunda en iyi on iş zekası yazılımını aşağıdaki sıralama ile belirlemiştir (Best Business Intelligence Software, 2021): 


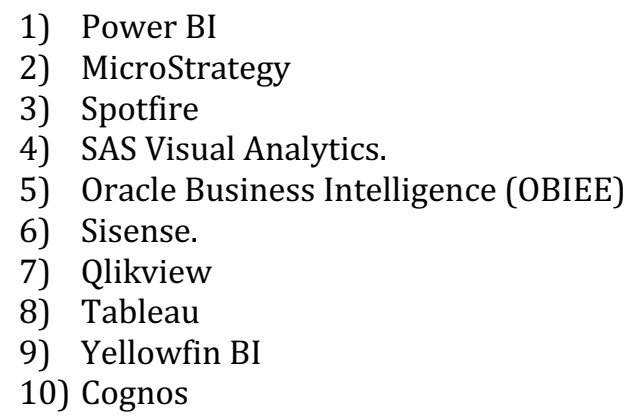

İş zekası uygulamalarının 2017 yılına ait pazar paylarını gösteren bir grafik, Şekil 2'de gösterilmiştir.

Şekil 2. İş Zekası Uygulamaları Pazar Payları (2017)

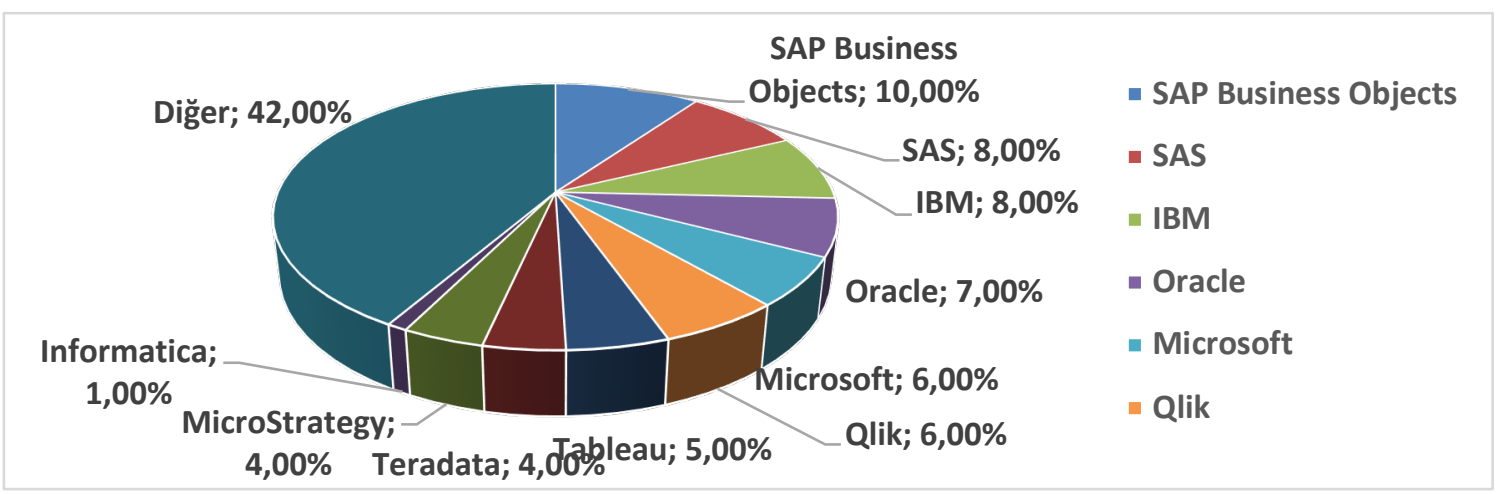

Kaynak: https://www.businessintelligencesoftware.co/bi-tools-market-share-2017.html

2017 yılına ait pazar payları incelendiğinde en yüksek pazar payının SAP Business Objects'e ait olduğu görülmektedir. Diğer dağılımlar incelendiğinde, \%42'lik bir pazar payının hala yerel uygulamalarda olduğu da oldukça dikkat çekmektedir.

İşletmeler iş zekası uygulamalarının seçiminde birçok seçeneği değerlendirmektedirler. Bu değerlendirme aşamasında gerek işletme ile ilgili gerekse de yazılım açısından dikkate alınan çeşitli kriterler bulunmaktadır. Literatür incelendiğinde, iş zekası uygulamalarının ÇKKV yöntemleri ile değerlendirildiği sınırlı sayıda çalışmaya rastlanmıștır.

2015 yılında Çetinyokuş ve Özdil, iş zekası seçiminde “BI SURVEY 7" raporu yazılım grupları özet verilerinden yararlanarak, CRITIC ve TOPSIS yöntemleri ile bir değerlendirme yapmışlardır (Çetinyokuş ve Özdil, 2015). 2016 yllında Hanine vd. (ETL) Ayıklama, dönüștürme ve yükleme yazılımı seçiminde AHP-TOPSIS yöntemlerini kullanmışlardır (Hanine vd., 2016). Hanine vd. 2017 yılında ise Jeo-uzamsal iş zekası seçimi için Delphi fuzzy AHP-PROMETHEE kullanmışlardır (Hanine, 2017).

Çalışmada kullanılan FUCOM yöntemi ÇKKV literatürüne son yıllarda giren bir kriter ağırlıklandırma yöntemi olmasına rağmen, birçok farklı alanda kullanıldı̆̆ı görülmektedir. Prentkovskis vd. (2018) hizmet kalitesinin ölçümündeki kalite boyutlarının ağırlık katsayılarının belirlenmesinde; Božanić (2019) köprü inşası için uygun yer seçiminde kullanılan kriterlerin ağırlıklarının belirlenmesinde; Fazlollahtabar vd. (2019) forklift araçları arasından en uygun alternatifin seçiminde dikkate alınan kriterlerin belirlenmesinde; Durmić (2019) tedarikçi seçim kriterlerinin değerlendirilmesinde; Dalić vd. (2020) dağıtım kanallarının belirlenen kriterlere göre değerlendirilmesi sürecinde kriterlerin önem ağırlıklarının belirlenmesinde; Ecer (2021a) rüzgar çiftliği yer seçimini etkileyen faktörlerin önem ağırlıklarının hesaplanmasında; Sofuoğlu ise (2020) en uygun üretim yöntemini seçmek için dikkate alınan kriterlerin ağırlıkların hesaplanmasında; Demir ve Bircan (2020) özel okul seçimini etkileyen kriterlerin önem ağırlıklarının hesaplanmasında; Ecer (2021b) tedarikçi seçiminde sürdürülebilirlik kriterlerinin önem ağırlıklarının belirlenmesinde FUCOM yöntemini kullanmıştır.

\section{FUCOM}

Pamucar vd. (2018) tarafından ÇKKV literatürüne kazandırılan FUCOM (Full Consistency Method-Tam Tutarlılık Yöntemi), kriterlerin önem ağırlıklarının hesaplanmasında kullanılan, sübjektif kriter ağırlıklandırma yöntemlerinden biridir. FUCOM yönteminde diğer kriter ağırlıklandırma yöntemlerine göre daha az sayıda ikili karşılaştırma yaparak çözüm elde etmek mümkündür. Bu yöntemde $n$ adet kriter 
için n-1 adet karşılaştırma yapılmaktadır (Ecer, 2020; 120). Ayrıca karmaşık bir yöntem olmaması ve grup karar verme süreçlerinde kullanılabilmesi bu yöntemin öne çlkan diğer özelliklerinden biridir.

FUCOM yönteminin üç aşamadan oluşan uygulama adımları aşă̆ıda gösterilmektedir (Pamucar vd., 2018; Ecer, 2020).

\section{Adım: Kriterlerin Önem Sırasına Göre Sıralanması}

Bu adımda karar probleminde yer alan kriterler, karar verici(ler) tarafından en önemliden en az önemliye doğru sıralanır. Böylelikle Eşitlik (1)'de gösterildiği üzere ağırlık katsayılarının beklenen değerlerine göre kriter sıralamaları elde edilir.

$$
C_{j(1)}>C_{j(2)>} \cdots>C_{j(k)}
$$

Eşitlik (1)'deki k, dikkate alınan kriterin derecesini temsil etmektedir. Karar verici tarafından eşit önem düzeyinde olduğu düşünülen kriterler olması durumunda ">" yerine "=" işareti kullanılabilir.

\section{Adım: Kriterlerin Karşılaştırmalı Önceliklerinin Belirlenmesi}

$\mathrm{Bu}$ adımda, bir önceki adımda karar verici(ler) tarafından önem sıralamaları belirlenen kriterlerin karşılaștırmalı öncelikleri $\left(\varphi_{k /(k+1)}\right)$ belirlenerek, Eşitlik 2'de gösterilen karşılaştırmalı öncelik vektörü elde edilir.

$$
\Phi=\left(\varphi_{1 / 2}, \varphi_{2 / 3}, \varphi_{3 / 4}, \cdots, \varphi_{k /(k+1)}\right)
$$

Eşitlik 2'de gösterilen $\varphi_{k /(k+1)}$ değeri, $C_{j(k)}$ kriterinin sıralamasının, $C_{j(k+1)}$ kriterinin sıralamasına göre avantajını temsil etmektedir.

FUCOM yönteminde karar verici(ler) kriterlerin karşılaştırmaları için tamsayı, ondalık sayı veya belirli ölçeklere ait değerleri kullanabilirler. Bu durum kriterlerin değerlendirmelerinin yapılmasında karar vericilere esneklik sağlamaktadır.

\section{Adım: Kriterlerin Önem Ağırlıklarının Hesaplanması}

Yöntemin son adımında karar probleminde yer alan kriterlerin nihai önem ağırlıkları $\left(w_{1}, w_{2}, \cdots>w_{n}\right)^{T}$ hesaplanmaktadır. Bu ağırlıkların hesaplanması için aşağıda yer alan iki koşulun sağlanması gereklidir.

Koşul 1: Ağırlık katsayılarının oranı Eşitlik (3)'te gösterildiği üzere, 2. Adımda belirlenen kriterlerin karşılaştırmalı öncelik değerlerine eşittir.

$$
\frac{w_{k}}{w_{k+1}}=\varphi_{k /(k+1)}
$$

Koşul 2: Ağırlık katsayılarının nihai değerleri, matematiksel geçişliliği sağlamalıdır. O halde,

$$
\begin{aligned}
& \varphi_{k /(k+1)} \times \varphi_{(k+1) /(k+2)}=\varphi_{k /(k+2)} \text { olmalıdır. Ayrıca; } \\
& \varphi_{k /(k+1)}=\frac{w_{k}}{w_{k+1}} \text { ve } \varphi_{(k+1) /(k+2)}=\frac{w_{k+1}}{w_{k+2}} \text { olduğundan dolayl } \frac{w_{k}}{w_{k+1}} \times \frac{w_{k+1}}{w_{k+2}}=\frac{w_{k}}{w_{k+2}} \text { olarak elde edilir. }
\end{aligned}
$$

Böylelikle, kriterlerin ağırlık katsayılarının nihai değerleri için sağlanması gerekli bir başka koşul Eşitlik (4)'te gösterilen şekilde elde edilir.

$$
\frac{w_{k}}{w_{k+2}}=\varphi_{k /(k+1)} \times \varphi_{(k+1) /(k+2)}
$$

Tam tutarlılık Eşitlik (3) ve (4)'te gösterilen koşulların sağlanması durumunda sağlanır. Bir başka ifadeyle bu şartların sağlanması durumunda tam tutarlılıktan sapma (TTS) minimum olur. Bu durumda maksimum tutarlılık sağlanır ve kriter ağırlıkları için hesaplanan değerler için TTS değeri $\chi=0$ olur.

Kriterlerin nihai önem ağırlıklarını hesaplayabilmek için Eşitlik (5)'te gösterilen doğrusal programlama modelinin çözülmesi gereklidir.

$$
\begin{gathered}
\operatorname{Min} \chi \\
\left|\frac{w_{j(k)}}{w_{j(k+1)}}-\varphi_{k /(k+1)}\right| \leq \chi, \quad \forall j \\
\left|\frac{w_{j(k)}}{w_{j(k+2)}}-\varphi_{k /(k+1)} \times \varphi_{(k+1) /(k+2)}\right| \leq \chi, \quad \forall j
\end{gathered}
$$




$$
\begin{aligned}
& \sum_{j=1}^{n} w_{j}=1 \\
& w_{j} \geq 0, \forall j
\end{aligned}
$$

Eşitlik (5)'te gösterilen doğrusal programlama modelinin çözülmesi ile kriterlerin nihai önem ağırlıkları $\left(w_{1}, w_{2}, \cdots>w_{n}\right)^{T}$ ve $\operatorname{TTS}(\chi)$ değeri hesaplanır.

\section{Uygulama}

Çalışmanın bu bölümünde iş zekası uygulamalarının seçiminde dikkate alınan kriterlerin önem ağırlıklarının FUCOM yöntemi ile hesaplandığı örnek bir uygulamaya yer verilmiştir. Uygulamanın akış şeması Şekil 3'te özetlenmiştir.

Şekil 3. Uygulamanın Akış Şeması

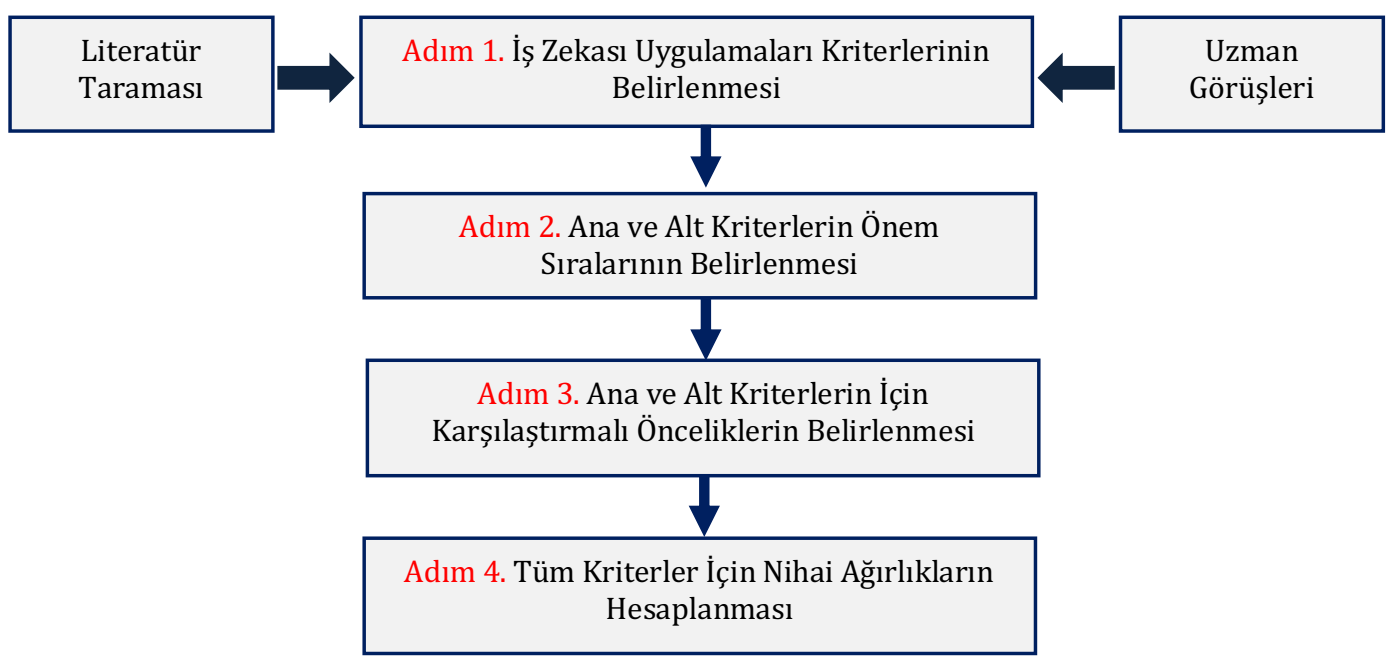

Uygulama kapsamında yer alan kriterler literatür taraması ve halihazırda çeşitli iş zekası uygulamaları kullanan bilgi teknolojisi yöneticilerinin görüşleri doğrultusunda oluşturulmuştur. Kriter listesi 3 ana kategoride olmak üzere toplam 21 adet kriterden oluşmaktadır. Ana kriterler ve bu kriterlerin altında yer alan kriterler aşağıda özetlenmiștir. Ana ve alt kriterlerin isimleri ve kriter numaraları ise Tablo 1'de sunulmuştur.

- İș (Projelendirme) Kriterleri; iş zekası uygulamasının projelendirilmesi aşamasında kurulum, uyarlama ve destek kısımlarına yönelik bir kriterdir. Ayrıca satın alma öncesi referanslar ve marka imajı da yine bu kriter altında gösterilmiştir.

- Görselleștirme Kriterleri; İş zekası uygulamasını nihayetinde bir raporlama amacından yola çıkılarak oluşturulmuştur. Farklı platformlardaki başarısı, görsel öğeler ve kullanıcının bu öğelerle etkileşimi bu ana kriterin altında toplanmıștır.

- Teknik Kriterler; İş zekası uygulamasının sahip olduğu teknik beceriler bu ana kriter altında toplanmıştır. API desteği, Bulut desteği, Bellekte çalışma gibi teknik bazı özellikler bu ana kriterin altında bir araya gelmiştir. Ayrıca büyük veri ve CBS gibi ayrıcalıklar da bu ana kriterin altında yer almaktadır.

Tablo 1. Uygulama Kapsaminda Yer Alan Kriterler

\begin{tabular}{ll}
\multicolumn{1}{c}{ ANA KRITERLER } & \multicolumn{1}{c}{ ALT KRITERLER } \\
\hline K1- İş (Projelendirme) Kriterleri & K11- Uyarlama Süresi \\
& K12- Uyarlama Maliyeti \\
& K13- Ylllı (Versiyon) Maliyet \\
& K14- Uzun Vadeli Kullanım \\
& K15- Partner Desteği \\
K16- Marka İmajı \\
K17- Referans
\end{tabular}


Tablo 1. Devam.

K2- Görselleştirme Kriterleri

K3- Teknik Kriterler

\author{
K21 - Farkı Platformlarda Kullanım \\ K22- Kullanıcı Ara yüzü Etkileşimi \\ K23- Gösterge Paneli \\ K24- Görsel Dizayn \\ K25- Detaylandırma Özellikleri \\ K26- Çevrimdışı Gösterim \\ K31- API Desteği \\ K32- Geliştirme Kolaylığı \\ K33- Veri Kaynakları ile Uyum \\ K34- Bellekte Çalışma Özelliği \\ K35- CBS Desteği \\ K36- Bulut Desteği \\ K37- Büyük Veri Analizi \\ K38- Güvenlik
}

FUCOM yöntemi ile kriterlerin önem ağırlıklarının hesaplanması sürecinde, üç farklı uzman karar verici yer almıştır. Uzman karar vericiler, uzun bir süredir iş zekası uygulamaları kullanan ve oldukça deneyimli bilgi teknolojisi yöneticileri arasından belirlenmiştir. Uygulamanın ilk adımında Tablo 2'de gösterilmiş olan kriterler, üç uzman karar verici tarafından önem düzeylerine göre sıralanmıştır. Ana kriterler ve alt kriterler için ayrı ayrı yapılan bu sıralamalar Tablo 2'te gösterilmiştir.

Tablo 2. Karar Vericilerin Önem Sıralamaları

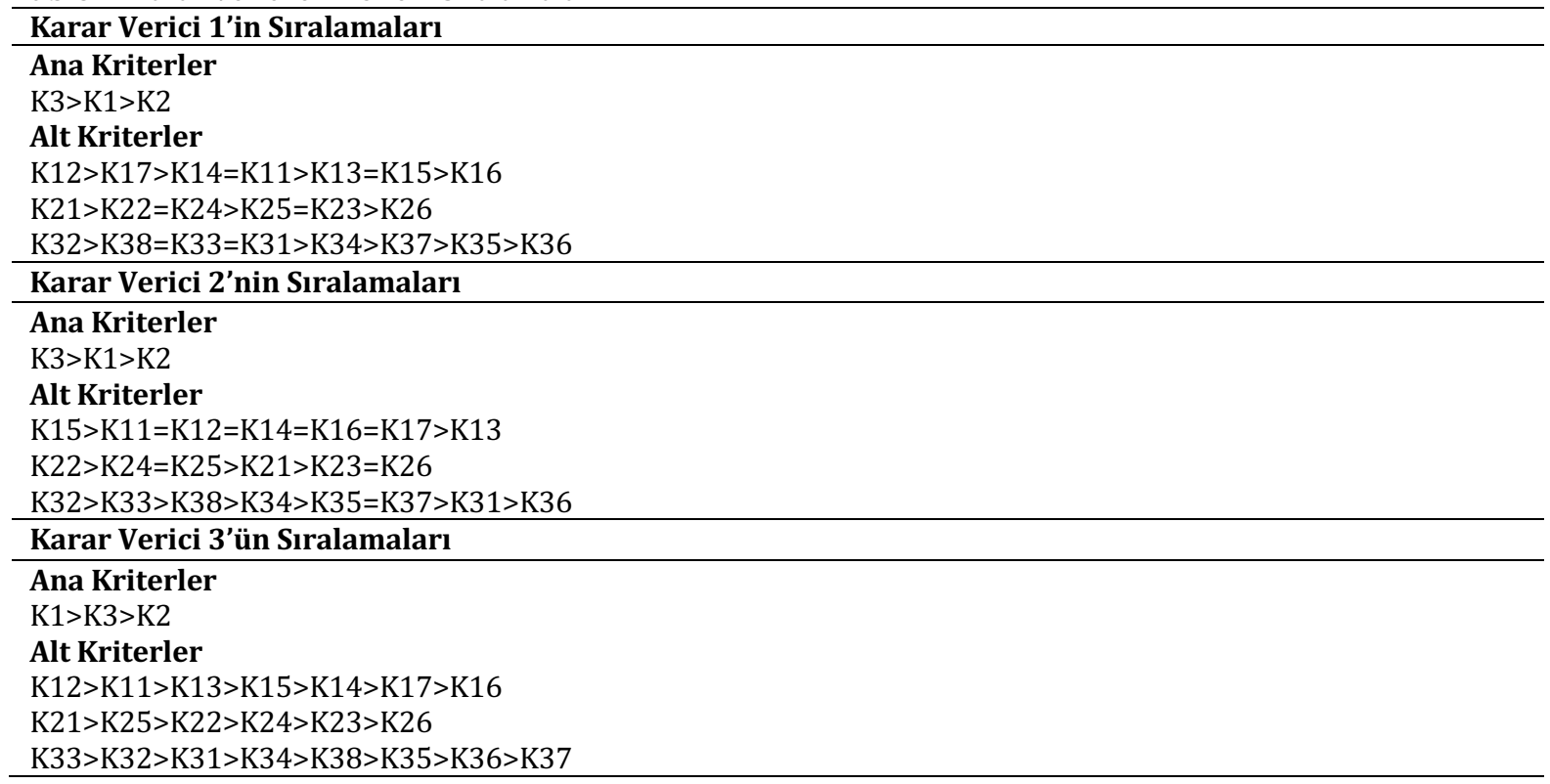

Tablo 2'de yer alan ">” işareti daha önemli, “=” işareti ise eşit düzeyde önemliyi temsil etmektedir. Uzman karar vericiler ana ve alt kriterleri kendi arasında önem sırasına koyduktan sonra, kriterlerin karşılaştırmalı önceliklerini 1-9 skalasına (1:Eşit; 9: En yüksek) göre belirlemişlerdir. Değerlendirmelerin tümü en önemli kriterin diğer kriterlere göre önceliğinin belirlenmesi mantığı ile oluşturulmuştur. Belirlenen karşılaştırmalı öncelikler ana kriterler için Tablo 3'de gösterilmiştir.

Tablo 3. Ana Kriterler İçin Değerlendirmeler

\begin{tabular}{llll}
\hline Karar Verici 1 & & & \\
\hline Ana Kriterler (Önem Sırası) & K3 & K1 & K2 \\
Değerlendirme & 1 & 3 & 4 \\
\hline Karar Verici 2 & & & \\
\hline Ana Kriterler (Önem Sırası) & K3 & K1 & K2 \\
Değerlendirme & 1 & 2 & \\
\hline Karar Verici 3 & & & K2 \\
\hline Ana Kriterler (Önem Sırası) & K1 & K3 & 5 \\
Değerlendirme & 1 & 3 & \\
\hline
\end{tabular}


Tablo 3'de yer alan ana kriterler için karșlaștırmalı öncelikler incelendiğinde uzman karar verici 1 için en önemli kriter teknik kriterler (K3) olarak belirlenmiştir. Bu karar verici teknik kriterlerin (K3) iş kriterlerinden(K1) 3 kat daha önemli, teknik kriterlerin (K3) görselleștirme kriterlerinden (K2) ise 4 kat önemli olduğunu düşünmektedir. Tablo 4'de gösterilen alt kriterler için yapılan değerlendirmeler de benzer mantıkla oluşturulmuştur.

Tablo 4. Alt Kriterler İçin Değerlendirmeler

\begin{tabular}{|c|c|c|c|c|c|c|c|c|}
\hline \multicolumn{9}{|l|}{ Karar Verici 1} \\
\hline İș Alt Kriterler (Önem Sırası) & K12 & K17 & K14 & K11 & K13 & K15 & K16 & \\
\hline Değerlendirme & 1 & 2 & 3 & 3 & 4 & 4 & 6 & \\
\hline Görselleștirme Alt Kriterler (Önem Sırası) & K21 & K22 & K24 & K25 & K23 & K26 & & \\
\hline Değerlendirme & 1 & 2 & 2 & 3 & 3 & 4 & & \\
\hline Teknik Alt Kriterler (Önem Sırası) & K32 & K38 & K33 & K31 & K34 & K37 & K35 & K36 \\
\hline Değerlendirme & 1 & 2 & 2 & 2 & 3 & 4 & 5 & 7 \\
\hline \multicolumn{9}{|l|}{ Karar Verici 2} \\
\hline İş Alt Kriterler (Önem Sırası) & K15 & K11 & K12 & K14 & K16 & K17 & K13 & \\
\hline Değerlendirme & 1 & 2 & 2 & 2 & 2 & 2 & 5 & \\
\hline Görselleștirme Alt Kriterler (Önem Sırası) & K22 & K24 & K25 & K21 & K23 & K26 & & \\
\hline Değerlendirme & 1 & 2 & 2 & 3 & 5 & 5 & & \\
\hline Teknik Alt Kriterler (Önem Sırası) & K32 & K33 & K38 & K34 & K35 & K37 & K31 & K36 \\
\hline Değerlendirme & 1 & 2 & 3 & 4 & 5 & 5 & 7 & 8 \\
\hline \multicolumn{9}{|l|}{ Karar Verici 3} \\
\hline İş Alt Kriterler (Önem Sırası) & K12 & K11 & K13 & K15 & K14 & K17 & K16 & \\
\hline Değerlendirme & 1 & 2 & 3 & 5 & 6 & 7 & 9 & \\
\hline Görselleștirme Alt Kriterler (Önem Sırası) & $\mathrm{K} 21$ & K25 & K22 & $\mathrm{K} 24$ & $\mathrm{~K} 23$ & K26 & & \\
\hline Değerlendirme & 1 & 2 & 3 & 4 & 5 & 7 & & \\
\hline Teknik Alt Kriterler (Önem Sırası) & K33 & K32 & K31 & K34 & K38 & K35 & K36 & K37 \\
\hline Değerlendirme & 1 & 2 & 3 & 4 & 5 & 6 & 7 & 9 \\
\hline
\end{tabular}

Yapılan değerlendirmelerden yararlanılarak tüm kriterlerin karşılaştırmalı öncelikleri hesaplanır. Tablo 3'te gösterilmiş olan Karar Verici 1'in ana kriterler için yaptığı karşılaştırmalı öncelikler aşağıdaki gibi gösterilmiştir.

$$
\varphi_{C 3 / C 1}=3 / 1=3 \text { ve } \varphi_{C 1 / C 2}=4 / 3=1,33
$$

Yöntemin son adımında tüm kriterler için karșllaștırmalı önceliklerden yararlanılarak kriter ağllıkları hesaplanacaktır. Eşitlik (3)'te gösterildiği üzere ağırlık katsayılarının oranı, kriterlerin karşılaştırmalı önceliğine eşit olduğundan dolayı Karar Verici 1 için değerlendirmeleri doğrultusunda ana kriterler için ağırlık katsayılarının oranı aşağıda gösterilen şekilde elde edilir.

$$
w_{C 3 / C 1}=3 \text { ve } w_{C 1 / C 2}=1,33
$$

Ağırlık katsayılarının nihai değerlerinin Eşitlik (4)'te gösterilen matematiksel geçişlilik koşulunu sağlaması gereklidir. Örneğin Karar Verici 1'in değerlendirmeleri doğrultusunda 3. Ana kriterin 2. Ana kritere göre değeri aşağıda gösterilen şekilde ifade edilir.

$$
\frac{w_{3}}{w_{2}}=w_{3 / 1} \times w_{1 / 2}=3 \times(4 / 3)=4
$$

Karar verici 1'in değerlendirmeleri sonucunda ana kriterler için nihai kriter ağırlıklarının elde edilmesi için Eşitlik (6)'da gösterilen doğrusal programlama modeli kurulur.

$$
\begin{gathered}
\left|\frac{w_{3}}{w_{1}}-3\right| \leq \chi,\left|\frac{w_{1}}{w_{2}}-1,33\right|,\left|\frac{w_{3}}{w_{2}}-4\right| \leq \chi \\
\sum_{j=1}^{3} w_{j}=1 \\
w_{j} \geq 0, \forall j
\end{gathered}
$$

Eşitlik (6)'da gösterilen doğrusal programlama modelinin Excel Solver ile çözülmesi ile Karar Verici-1 için ana kriterlerin nihai önem ağırlıkları $w_{1}=0,210, w_{2}=0,158, w_{3}=0,632$ olarak hesaplanır. Eşitlik (6)'da gösterilen modelin çözüm değerleri ve tam tutarlılıktan sapma değerini gösteren Excel Solver ekran görüntüsü Şekil 4'te gösterilmiştir. 
Şekil 4. Karar Verici-1'in Ana Kriterlere Göre Değerlendirmeleri ve Çözüm Ekranı

\begin{tabular}{|c|c|c|c|c|}
\hline$\Delta$ & A & B & C & D \\
\hline \multicolumn{5}{|l|}{1} \\
\hline 2 & Kriter Sayısı $=3$ & Kriter 1 & Kriter 2 & Kriter 3 \\
\hline 3 & Kriter Adı & K1 & K2 & K3 \\
\hline 4 & Sira & 2 & 3 & 1 \\
\hline \multicolumn{5}{|l|}{5} \\
\hline \multicolumn{5}{|l|}{6} \\
\hline 7 & Kriterler (Önem sırasına göre) & K3 & K1 & K2 \\
\hline 8 & Karşılaştırmalı öncelikler & 1 & 3 & 4 \\
\hline \multicolumn{5}{|l|}{9} \\
\hline \multicolumn{5}{|l|}{10} \\
\hline 11 & \multirow{2}{*}{ Ağırlıklar } & K3 & K1 & K2 \\
\hline 12 & & 0,632 & 0,211 & 0,158 \\
\hline 13 & & & & \\
\hline 14 & $\operatorname{TTS}(\mathrm{x})$ & 0,000 & & \\
\hline
\end{tabular}

Tüm karar vericilerin ana ve alt kriterler için yaptıkları değerlendirmelerden yararlanılarak ayrı ayrı doğrusal programlama modelleri oluşturulmuştur. Bu modellerin çözülmesi ile ana kriterlerin önem ağırlıkları Tablo 5'te, alt kriterlerin önem ağırlıkları ise Tablo 6'da gösterilen şekilde hesaplanmıştır. Her karar verici için ayrı ayrı hesaplanan ağırlıkların ortalaması alınarak, yerel ağırlıklar en son sütunda yer alacak șekilde hesaplanmıştır.

Ayrıca tam tutarlılıktan sapma değerleri tüm modellerin çözümü sonucunda "0" olarak elde edilmiştir. Tam tutarlılıktan sapma, hesaplanan ağırlık katsayılarının kriterlerin tahmini karşılaştırmalı önceliklerinden sapma değeridir. Tam tutarlılıktan sapma hesaplanarak tahmin edilen ağırlık katsayılarının güvenirliliği test edilir ve tam tutarlılıktan sapma değerinin sıfıra çok yakın olması durumu istenilen bir durumdur.

Tablo 5. Ana Kriterler İçin Yerel Önem Ağırlıkları

\begin{tabular}{ccccc}
\hline Ana Kriterler & Karar Verici-1 & Karar Verici-2 & Karar Verici-3 & Yerel Ağırlık \\
\hline K1 & 0,210 & 0,286 & 0,652 & 0,383 \\
K2 & 0,158 & 0,143 & 0,131 & 0,473 \\
K3 & 0,632 & 0,571 & 0,217 & 0,144 \\
\hline
\end{tabular}

Tablo 6. Alt Kriterler İçin Yerel Önem Ağırlıkları

\begin{tabular}{ccccc}
\hline İs Alt Kriterler & Karar Verici-1 & Karar Verici-2 & Karar Verici-3 & Yerel A ğırlık \\
\hline K11 & 0,118 & 0,135 & 0,204 & 0,152 \\
K12 & 0,353 & 0,135 & 0,408 & 0,299 \\
K13 & 0,088 & 0,054 & 0,136 & 0,093 \\
K14 & 0,118 & 0,135 & 0,068 & 0,107 \\
K15 & 0,088 & 0,270 & 0,082 & 0,147 \\
K16 & 0,059 & 0,135 & 0,045 & 0,080 \\
K17 & 0,176 & 0,135 & 0,058 & 0,123 \\
G21 Alt Kriterler & & & & 0,292 \\
K22 & 0,343 & 0,122 & 0,412 & 0,225 \\
K23 & 0,171 & 0,366 & 0,137 & 0,090 \\
K24 & 0,114 & 0,073 & 0,082 & 0,152 \\
K25 & 0,171 & 0,183 & 0,103 & 0,168 \\
K26 & 0,114 & 0,183 & 0,206 & 0,073 \\
K31 & 0,086 & 0,073 & 0,059 & 0,107 \\
K32 & & & & 0,280 \\
K33 & 0,146 & 0,052 & 0,123 & 0,233 \\
K34 & 0,292 & 0,363 & 0,185 & 0,093 \\
K35 & 0,146 & 0,182 & 0,370 & 0,064 \\
K36 & 0,097 & 0,091 & 0,092 & 0,047 \\
K37 & 0,058 & 0,073 & 0,062 & 0,062 \\
K38 & 0,042 & 0,045 & 0,053 & 0,114 \\
\hline
\end{tabular}


Son olarak, Tablo 5 ve 6 'da gösterilmiş olan ana kriter ağırlıkları ile alt kriterlerin yerel ağırlıklarının çarpılmasıyla tüm alt kriterlerin global ağırlıkları hesaplanır. Hesaplanan nihai kriter ağırlıkları Tablo 7'de gösterilmiştir.

Tablo 7. Kriterlerin Nihai Önem Ağırlkkları ve Sıralama

\begin{tabular}{cccc}
\hline Ana Kriterler & Alt Kriterler & Global Ağırlkklar & Siralama \\
\hline \multirow{5}{*}{ K1 $(0,383)$} & K11 $(0,152)$ & 0,058 & 6 \\
& K12 $(0,299)$ & 0,114 & $\mathbf{2}$ \\
& K13 $(0,093)$ & 0,035 & 12 \\
& K14 $(0,107)$ & 0,041 & 10 \\
& K15 $(0,147)$ & 0,056 & 15 \\
& K16 $(0,080)$ & 0,031 & 8 \\
K2 $(0,473)$ & K17 $(0,123)$ & 0,047 & $\mathbf{1}$ \\
& K21 $(0,292)$ & 0,138 & 9 \\
& K22 $(0,225)$ & 0,106 & 5 \\
& K23 $(0,090)$ & 0,042 & 4 \\
K24 $(0,152)$ & 0,072 & 13 \\
& K25 $(0,168)$ & 0,079 & 11 \\
K3 $(0,144)$ & 0,034 & 14 \\
& K26 $(0,073)$ & 0,015 & 18 \\
& K31 $(0,107)$ & 0,040 & 19 \\
& K32 $(0,280)$ & 0,034 & 21 \\
& K33 $(0,233)$ & 0,013 & 20 \\
K34 $(0,093)$ & 0,009 & 16 \\
\hline
\end{tabular}

Tablo 7'de gösterilmiş olan nihai kriter ağırlıkları incelendiğinde, iş zekası uygulamalarının seçiminde dikkate alınan en önemli ana kriterin \%47,3 ile K2- görselleștirme olduğu tespit edilmiştir. Görselleștirme kriterlerini sırasıyla \%38,2 ile K1-iş(projelendirme) kriterleri ve \%14,4 ile teknik kriterler takip etmiştir.

Tüm alt kriterlere ait global ağırlıklar dikkate alındığında, en önemli kriterin \%13,8 ile K21-farklı platformlarda kullanım olduğu tespit edilmiştir. Bu kriteri sırasıyla \%11,4 ile K12-uyarlama maliyeti ve \%10,6 ile K22-kullanıcı ara yüzü etkileşimi kriterleri takip etmiştir. Tüm kriterler için hesaplanan nihai kriter ağırlıkları Şekil 5'te gösterilmiștir.

Şekil 5. Kriterlerin Önem Ağırlıkları

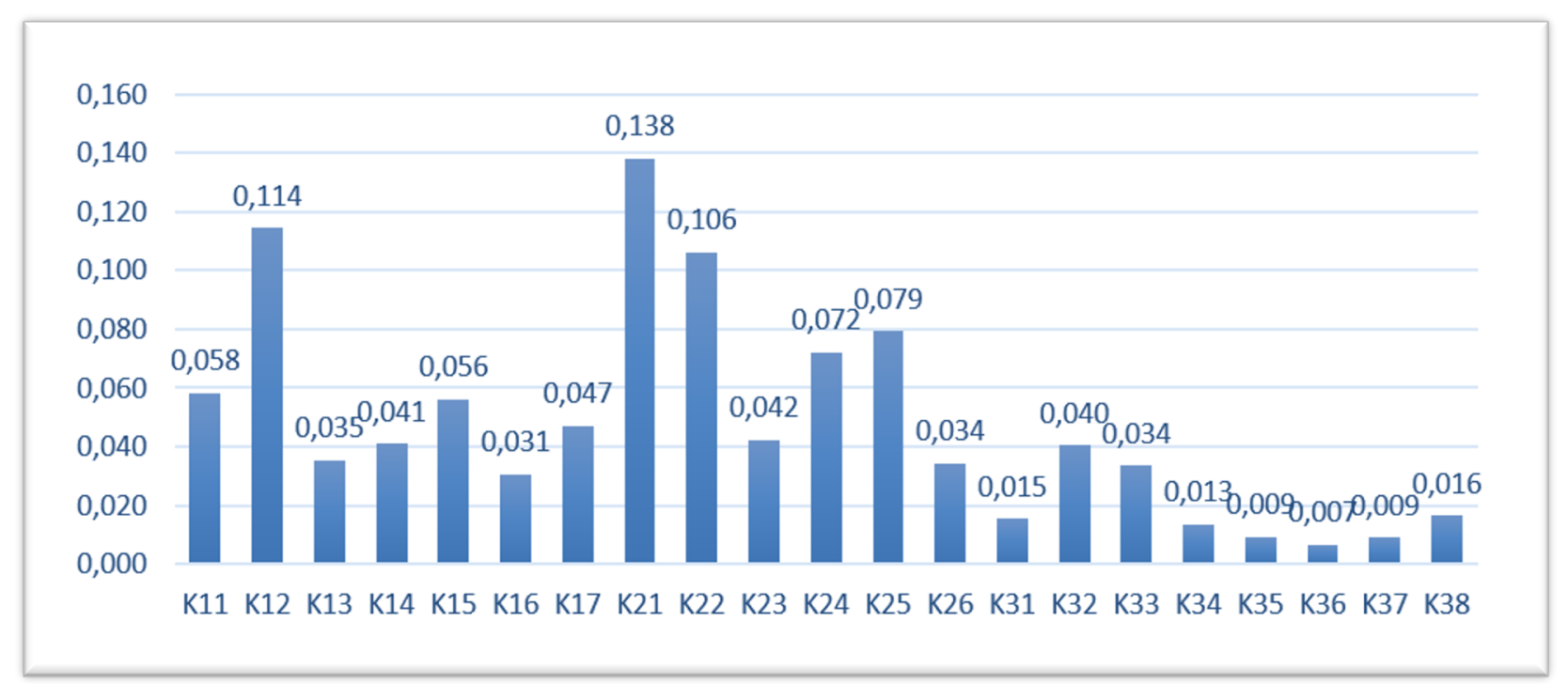

\section{Sonuç ve Öneriler}

İşletmeler için oldukça önemli olan verilerin depolanmasının önemi arttığından dolayı, iş zekası uygulamalarının kullanımı artmıştır. Verinin görselleştirilmesi ve değerli bilgiye dönüşümü açısından son derece önemli olan iş zekası uygulamalarının seçimi, işletmeler için önemli ve zor bir karar olmaktadır. Bu çalışmada işletmelerin iş zekası uygulamalarına yönelik karar verme süreçlerine destek olacak bir 
uygulama yapılmıştır. Uygulama kapsamındaki kriterler literatür taraması ve bilişim sektöründe çalışan uzmanların görüşleri alınarak oluşturulmuştur. Belirlenen üç ana kriter ve yirmi bir adet alt kritere ilişkin önem ağırlıklarının belirlenmesi amacıyla, subjektif bir ağırlıklandırma yöntemi olan FUCOM yönteminden yararlanılmıştır.

Çalışma sonucunda ana kriterler önem sırasına göre görselleştirme kriterleri, iş(projelendirme) kriterleri ve teknik kriterler olarak belirlenmiştir. Alt kriterler global olarak değerlendirildiğinde en önemli üç kriter sırasıyla; farklı platformlarda kullanım, uyarlama maliyeti ve kullanıcı ara yüzü etkileşimi olarak tespit edilmiştir. En az önemli üç alt kriter ise sırasıyla; bulut desteği, büyük veri analizi ve CBS desteği olarak bulunmuştur. Bulgular uzmanların iş zekası uygulamalarında görsel öğelere daha fazla önem verdiğini göstermiştir. Alt kriterler açısından bakıldığında ise, iş zekası uygulamalarının diğer teknolojilerle uyumundan ziyade temel kullanım özellikleri ve maliyetinin önemli olduğu tespit edilmiştir.

Çalışma, işletmeler açısından son derece zor ve önemli bir karar olan iş zekası seçimine yönelik dikkate alınması gereken kriterler ve bu kriterlerin önem ağırlıklarının hesaplanmasına yönelik bir model oluşturmaktadır. Mevcut çalışmanın gerek ulusal literatürde FUCOM yöntemi ile ilgili az sayıda çalışma bulunması, gerekse de iş zekası uygulamalarının seçimi gibi karmaşık bir konuya model oluşturması nedeniyle literatüre katkı sağlaması beklenmektedir. Gelecek çalışmalarda, farklı kriter yapıları incelenebilir veya benzer kriter yapısının bulanık mantık ile entegre kriter ağırlıklandırma yöntemleri (bulanık SWARA, bulanık BWM vb.) ile analizi gerçekleştirilebilir. Ayrıca alternatif sıralama amacıyla kullanılan TOPSIS, MABAC, MARCOS, WASPAS vb. yöntemler ile iş zekası uygulama alternatiflerinin değerlendirileceği çalışmalar yapılabilir.

Araştırmacıların Katkı Oranı Beyanı: Yazarlar, makaleye katkılarının eşit olduğunu beyan etmişlerdir.

Destek ve Teşekkür Beyanı: Yazarlar, destek ve teşekkür beyanında bulunmamışlardır.

Çatışma Beyanı: Yazarlar, kendileri ve üçüncü taraflar açısından herhangi bir çıkar çatışmasının olmadığını beyan etmişlerdir.

Etik Kurul Raporu Gerekliliği Beyanı: Yazarlar, makalede etik kurul raporuna ihtiyaç duyulmadığını beyan etmișlerdir. 


\section{Kaynakça}

Best Business Intelligence Software, (2021). https://www.businessintelligencesoftware.co/best-businessintelligence-software-2021.html (Erişim tarihi: 02.02.2021).

Božanić, D., Tešić, D. \& Kočić, J. (2019). Multi-criteria FUCOM-Fuzzy MABAC model for the selection of location for construction of single-span bailey bridge. Decision Making: Applications in Management and Engineering, 2(1), 132-146.

Çetinyokuş, T. \& Özdil, L. (2015). İş zekası yazılımı alternatiflerinin çok kriterli karar verme yöntemi ile değerlendirilmesi. Yönetim Bilişim Sistemleri Dergisi, 1(2), 48-61.

Dalić, I., Stević, Ž., Erceg, Ž., Macura, P. \& Terzić, S. (2020). Selection of a distribution channel using the integrated FUCOM-MARCOS Model. Faculty of Business Economics and Entrepreneurship, (3-4), 91107.

Demir, G. \& Bircan, H. (2020). Kriter Ağırlıklandırma Yöntemlerinden BWM ve FUCOM Yöntemlerinin Karşılaștırılması ve Bir Uygulama. Cumhuriyet Üniversitesi Íktisadi ve Ídari Bilimler Dergisi, 21(2), 170-185.

Durmić, E. (2019). Evaluation of criteria for sustainable supplier selection using FUCOM method. Operational Research in Engineering Sciences: Theory and Applications, 2(1), 91-107.

Ecer, F. (2021a). FUCOM sübjektif ağırlıklandırma yöntemi ile rüzgâr çiftliği yer seçimini etkileyen faktörlerin analizi. Pamukkale Üniversitesi Mühendislik Bilimleri Dergisi, 27(1), 24-34.

Ecer, F. (2020). Çok Kriterli Karar Verme: Geçmişten Günümüze Kapsamlı Bir Yaklaşım. Seçkin Yayınevi, Ankara.

Ecer, F. (2021b). Sürdürülebilir Tedarikçi Seçimi: FUCOM Sübjektif Ağırlıklandırma Yöntemi Temelli MAIRCA Yaklaşımı. Mehmet Akif Ersoy Üniversitesi İktisadi ve İdari Bilimler Fakültesi Dergisi, 8(1), 26-48.

Fazlollahtabar, H., Smailbašić, A. \& Stević, Ž. (2019). FUCOM Method In Group DecisionMaking: Selection Of Forklift In A Warehouse, Decision Making: Applications in Management and Engineering, 2(1), 49-65.

Gartner. (2020). Gartner Magic Quadrant Report, 2020.

Hanine, M., Boutkhoum, O., Tikniouine, A. \& Agouti, T. (2016) Application of an integrated multi-criteria decision making AHP-TOPSIS methodology for ETL software selection. SpringerPlus. 5(1), 1-17.

Hanine, M., Boutkhoum, O., Agouti, T. \& Tikniouine, A. (2017). A new integrated methodology using modified Delphi-fuzzy AHP-PROMETHEE for Geospatial Business Intelligence selection. Information Systems and e-Business Management, 15(4), 897-925.

Horakova, M. \& Skalska, H. (2013). Business intelligence and implementation in a small enterprise. Journal of systems integration, 4(2), 50-61.

IBM (2021). Business Intelligence. https://www.ibm.com/analytics/business-intelligence/(Erişim tarihi: 15.02.2021).

İş Zekası ve Ötesi. (2014, 24 Ağustos). En iyi iş zekası uygulamaları listesinde son durum. http://iszekasiveotesi.blogspot.com/2014/ (Erişim tarihi: 15.02.2021).

Karim, A.J. (2011). The value of Competitive Business Intelligence System (CBIS) to stimulate competitiveness in global market. International Journal of Business Intelligence and Social Science. 2(19), 196-203.

Khan, A. (2012). Business Intelligence and data warehousing simplified: 500 questions, answers, and tips. Dulles, VA: Mercury Learning and Information, 2012. eBook Collection (EBSCOhost), EBSCOhost (Erişim tarihi: 03.02.2021).

Luhn, H.P. (1958). A Business Intelligence System, IBM Journal 2(4), 314-319.

Mike, B. (2003). Business Intelligence for the Enterprise. PrenticeHall PTR.

Moss, L.T. \& Atre, S. (2003). Business intelligence roadmap: the complete project lifecycle for decision-support applications. Addison-Wesley Professional. 
Pamucar, D., Stević, Ž. \& Sremac, S. (2018). A new model for determining weight coefficients of criteria in MCDM models: Full consistency method (FUCOM). Symmetry, 10(9), 393.

Pavkov, S., Poščić, P. \& Jakšić, D. (2016). Business Intelligence Systems yesterday, today and tomorrow-an overview. Zbornik Veleučilišta u Rijeci, 4(1), 97-108.

Prentkovskis, O., Erceg, Ž., Stević, Ž., Tanackov, I., Vasiljević, M. \& Gavranović, M. (2018). A new methodology for improving service quality measurement: Delphi-FUCOMSERVQUAL model. Symmetry, 10(12), 757.

Sofuoğlu, M.A. (2020). Fuzzy applications of FUCOM method in manufacturing environment. Politeknik Dergisi, 23(1), 189-195.

BI Tools Market Share (2017). https://www.businessintelligencesoftware.co/bi-tools-market-share2017.html (Erişim Tarihi: 03.02.2021). 